that this tumour may be induced by an environmental factor. The age distribution both in the indigenous and in the immigrant population suggests that this factor produces immunity in the majority of people exposed to it and tumour only in rare instances. The apparent dependence on temperature of the tumour distribution suggests that the environmental agent is transmitted by an insect vector and that either the distribution of the vector or the development of the agent within the vector is dependent on temperature. This agent might be an arbovirus or other insect-vectored virus; it could also be some other form of parasitic disease such as malaria.

\section{Summary}

This report gives a detailed analysis of the age, tribal, and geographical distribution of 450 histologically proved cases of the African lymphoma seen in Uganda over the past eight years. There is a twentyfold difference between the tumour incidence in the lowland areas along the Nile, where the tumour is most common, and the incidence in the mountainous area of south-western Uganda, where the tumour is least common. This variation in incidence within Uganda correlates closely with variations in temperature. The average age in the tumour cases is lowest where the tumour is most common and highest where the tumour is least common.

The incidence of jaw involvement in the Uganda cases of African lymphoma varies inversely with the age of the patient. It is $100 \%$ at the age of 3 and falls progressively thereafter. Although the African lymphoma is rare in adults indigenous to the lowland areas of Uganda, almost half the cases occurring in immigrants from the "lymphoma-free" mountainous area of Rwanda and Burundi are over the age of 15 years.

These observations support the hypothesis that the African lymphoma may be induced by an insect-vectored agent that may be a virus. It is suggested that the majority of people exposed to this agent develop immunity to it and that in only rare instances is the tumour induced.

All the illustrations are gratefully acknowledged to W. Serumaga and E. Busulwa, of the Department of Medical Illustration in the Makerere University College Medical School. Fig. 8 was taken from the fournal of Dental Research.

We also wish to thank the doctors in Government and Mission hospitals throughout the country for their co-operation, without which these investigations could not be undertaken.

We are indebted to the Kampala Cancer Registry for much of the information, and to Dorothy Griffin for invaluable secretarial assistance.

The British Empire Cancer Campaign have provided financial assistance to make this work possible.

\section{REFERENCRS}

Burkitt, D. (1962). Brit. med. f., 2, 1019.

(1963). In International Review of Experimental Pathology, vol. 2 , ed. G. W. Richter and M. A. Epstein. Academic Press, New York. Epstein, M. A., Henle, G., Achong, B. G., and Barr, Y. M. (1965). F. exp. Med., 121, 761 .

Haddow, A. J. (1964). E. Afr. med. ₹., 41, 1.

Simons, P. J., and Ross, M. G. R. (1963). Ann. Rep. Imp. Cancer Res. Fund, p. 48. London.

Woodall, J. P., and Haddow, A. J. (1962). E. Afr. Res. Inst. Rep., p. 30. Wright, D. H. (1963) Brit. f. Cancer, 17, 50 .

\title{
Recurrence of Aortic Coarctation after Operation in Childhood
}

\author{
CLIFFORD G. PARSONS,* M.D., F.R.C.P. ; ROY ASTLEY, $†$ M.D., D.M.R.
}

Brit. med. F., 1966, 1, 573-577

Evidence about the results of operating on small children with coarctation of the aorta is conflicting, and there is still doubt whether the anastomosis grows with the child. "Until definite evidence can be obtained that an aortic anastomosis made during childhood will remain adequate in size in adult life, operation is better deferred until about the age of 15 in children without symptoms" (Sellors and Hobsley, 1963). Schuster and Gross (1962) advise the use of interrupted sutures because spaces between the stitches can allow growth to occur. Continuous sutures, technical difficulties caused by a long narrow segment of aorta, and operating on seriously ill infants are all factors which are thought to reduce the chance of obtaining a satisfactory anastomosis (Mustard et al., 1955 ; Bull et al., 1963).

Few accounts of restenosis have been published, however, either because of reluctance to record poor operative results or because such cases are rare. Rathi and Keith (1964) have reviewed the long-term results in 150 children who were treated surgically before they were 15 years old. Of these, 27 had an operation in their first year. They conclude that there is usually adequate growth of the anastomotic site even if operation is performed in infancy, and they found no evidence to indicate development of obstruction or restenosis from lack of localized arterial growth.

\footnotetext{
- Physician, Birmingham United Hospital and Children's Hospital, Birmingham. † Radiologist, Children's Hospital, Birmingham.
}

About a quarter of patients with coarctation die during infancy (Blackford, 1928), but a child surviving the first year is unlikely to die before its tenth birthday (Reifenstein et al., 1947). The mortality rate increases again in the second decade, and it is therefore unwise to delay operation after puberty (d'Abreu and Parsons, 1956). Rathi and Keith (1964) advise operation between 3 and 6 years of age, but in the large series of cases reported by Schuster and Gross (1962) operative mortality was at its lowest $(1.6 \%)$ at about the tenth year. In infancy surgical mortality is much higher, Nadas (1963) quoting a range "from 25 to $40 \%$, without guarantee of satisfactory and permanent relief of the hypertension." For this reason most paediatricians believe that heart failure associated with coarctation in infancy should be treated medically and that operation should be advised only in resistant cases (Lang and Nadas, 1956 ; Freundlich et al., 1961).

Persistent heart failure has made it necessary for us to advise operation on 13 babies, and three of these died. Among the survivors five appeared to develop recurrence of their aortic stricture. Other examples of restenosis have been observed in five older children. It is with these 10 cases of recurrent coarctation that this paper is concerned.

Before operation all the patients were shown to have localized constriction of the aortic arch, and this was confirmed by the pathologists who examined specimens after excision. In addition, three children had a somewhat narrow hypoplastic segment above the abrupt constriction. Some complicating 
abnormality was found in all the infants whose heart failure proved intractable. The clinical features are summarized in the Table.

\section{Group 1. Immediate Recurrence of Stenosis}

In four children recurrence of aortic obstruction was noted within a few hours of operation. The first of these (Case 1) is readily explained, because at the conclusion of a difficult operation a longitudinal split appeared in the aortic wall distal to the anastomosis. In order to control bleeding and to prevent

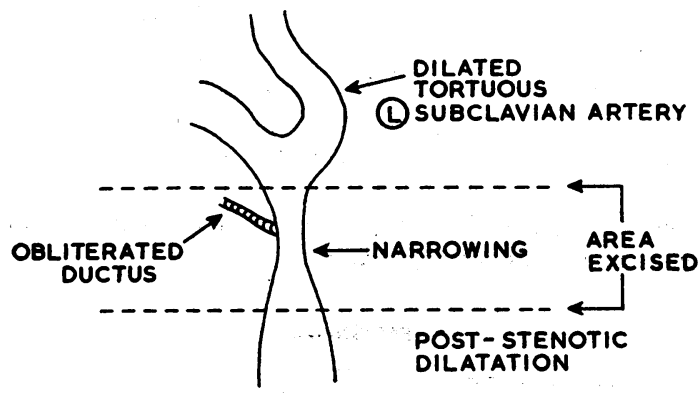

FIG 1.-Typical pinhole opening at level of constriction of aorta on examining excised segment. Replica of drawing by surgeon at operation.

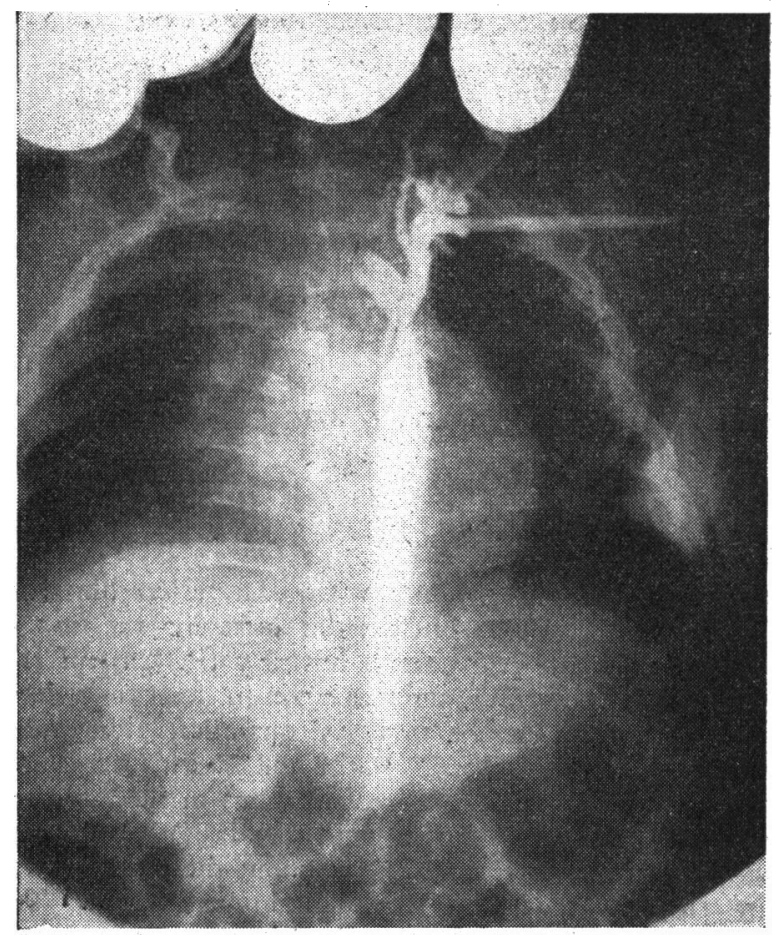

FIG. 2.-Case 2. Aortogram two months after operation. further splitting the surgeon was forced to divide and ligate the aorta. As a result the blood-pressure in the arms rose immediately to $230 / 160$, but after a satisfactory repair had been achieved at a second operation some two months later it fell rapidly to $120 / 70$ and remained satisfactory during the followup period.

The other three children developed signs of restenosis within a few hours of operation.

Fig. 1 reproduces the surgeon's sketch at the time of operation in Case 2. It shows clearly the lines of excision and also demonstrates that there was no hypoplasia of the arch. The pathologist described the specimen which he received as a segment of aorta with severe coarctation and a pinhole orifice. Two months after operation an aortogram (Fig. 2) confirmed that coarctation had again developed.

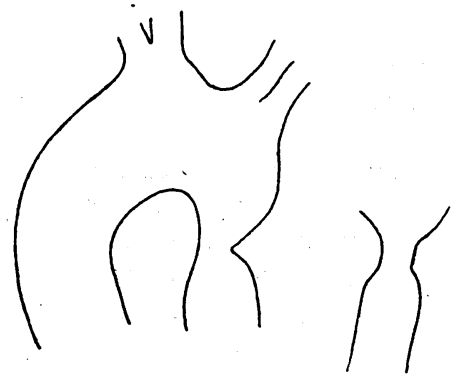

FIG. 3.-Case 3. Tracing of cineangiogram.

Restenosis was demonstrated by venous angiocardiography in Case 3 only two weeks after operation (Fig. 3). This infant's aortic arch had been hypoplastic above the coarctation, but the narrowing was not severe and was insufficient to cause any difficulty at operation. A satisfactory end-to-end anastomosis was obtained by making an oblique incision in the upper seg-

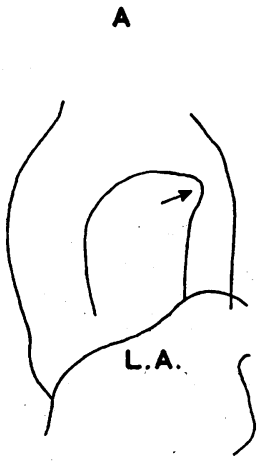

L.A.O.
L.A.O.

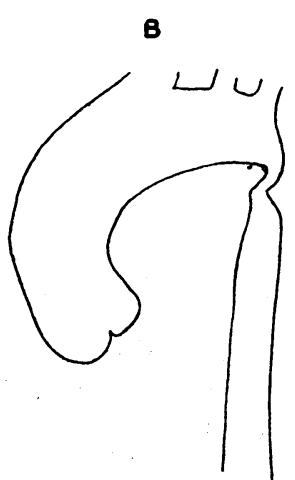

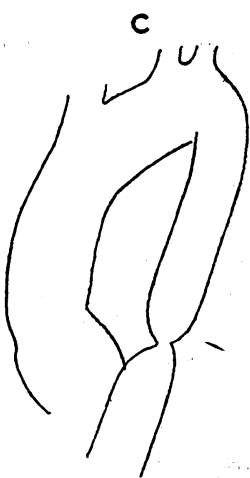

P. A.
Fig, 4-Case 4. A, Tracing of cineaortogram, left oblique position, December 1960. Age 7 years. B, Tracing of cineaortogram, left oblique position, January 1963. C, Tracing of cineangiogram, postero-anterior position, May 1964.

\begin{tabular}{|c|c|c|c|c|c|c|c|c|c|c|c|c|c|}
\hline \multirow{2}{*}{$\begin{array}{l}\text { Cane } \\
\text { No. }\end{array}$} & \multirow{2}{*}{ Sex } & \multicolumn{5}{|c|}{ Pre-operative Clinical Features } & \multicolumn{3}{|c|}{ Operation } & \multicolumn{2}{|c|}{ Recurrence } & \multicolumn{2}{|c|}{ Post-operative B.P. } \\
\hline & & $\begin{array}{c}\text { Femoral } \\
\text { Pulse }\end{array}$ & $\begin{array}{l}\text { B.P., } \\
\text { Arm }\end{array}$ & E.C.G. & $\begin{array}{c}\text { Heart } \\
\text { Failure }\end{array}$ & Complications & Age & Type & Suture & When & $\begin{array}{c}\text { Proved } \\
\text { by }\end{array}$ & Arm & Leg \\
\hline $\begin{array}{l}\mathbf{1} \\
\frac{2}{3}\end{array}$ & $\underset{\mathbf{M}}{\mathbf{M}}$ & $\begin{array}{l}0 \\
0 \\
+\end{array}$ & $\begin{array}{l}160 / 100 \\
220 / 120 \\
110 / 3\end{array}$ & $\begin{array}{l}\mathrm{LV}+ \\
\mathrm{LV}+ \\
\mathrm{LV}+\end{array}$ & $\overline{+}$ & $\begin{array}{l}\text { Turner's syndrome } \\
\text { P.D.A., fibroelastosis, } \\
\text { hypoplastic arch }\end{array}$ & $\begin{array}{l}12 \\
8 \mathrm{~m} \\
9 \mathrm{~m} .\end{array}$ & $\begin{array}{c}\text { End/end } \\
" 3\end{array}$ & $\begin{array}{l}\text { Contin. } \\
\text { Inter. }\end{array}$ & $\begin{array}{c}\text { Immediate } \\
\text { \# }\end{array}$ & $\begin{array}{l}\text { Operation } \\
\text { Aortogram } \\
\text { Angio- } \\
\text { cardiogram }\end{array}$ & $\begin{array}{l}230 / 160 \\
170 / 90 \\
110 / ?\end{array}$ & $\begin{array}{r}? \\
? \\
? \\
?\end{array}$ \\
\hline$\frac{4}{5}$ & $\mathbf{M}$ & $\begin{array}{l}0 \\
+\end{array}$ & $\begin{array}{l}150 / 80 \\
180 / 115\end{array}$ & $\begin{array}{l}\mathrm{RV}+ \\
\mathbf{L V}+\end{array}$ & $\overline{-}$ & $\begin{array}{l}\text { Pulmonary stenosis } \\
\text { Blood urea }\end{array}$ & $\begin{array}{l}10 \\
12\end{array}$ & $\begin{array}{l}\text { Graft } \\
\text { End/end }\end{array}$ & Cöntin. & 4 years & Operation & $\begin{array}{l}120 / 80 \\
160 / 120 \rightarrow 194 / 140\end{array}$ & $140 / 110$ \\
\hline 6 & $\mathbf{M}$ & + & $140 / 85$ & LV+ & - & Hypoplastic arch & 8 & " & Inter. & 43 & Aortogram, & $140 / 75 \rightarrow 165 / 90$ & $85 / 65$ \\
\hline 7 & $\mathbf{M}$ & $\mathbf{0}$ & $180 / 110$ & $\mathbf{R V}+$ & + & V.S.D., hypoplastic & $5 \mathrm{~m}$. & ” & " & 4 months & "》 & $120 / 2 \rightarrow 150 / 90$ & $110 / ?$ \\
\hline $\begin{array}{l}8 \\
9 \\
0\end{array}$ & $\begin{array}{l}\mathbf{M} \\
\mathbf{F}\end{array}$ & $\begin{array}{l}+ \\
0 \\
0\end{array}$ & $\begin{array}{l}120 / ? \\
150 / 110 \\
230 / ?\end{array}$ & $\begin{array}{l}\mathbf{R V +} \\
\mathbf{R V +} \\
\mathbf{L V +}\end{array}$ & $\frac{t}{t}$ & $\begin{array}{l}\text { P.D.A. } \\
\text { V.S.D. }\end{array}$ & $\begin{array}{l}6 \text { wks } \\
13 \\
5 \mathrm{~m} .\end{array}$ & $\begin{array}{l}\text { Plastic } \\
\text { End/end } \\
\text { » }\end{array}$ & $"$ & $\begin{array}{l}18 \\
8 \text { years }\end{array}$ & $\begin{array}{c}\text { Aortogram } \\
\text { Aortogram, } \\
\text { catheter }\end{array}$ & $\begin{array}{c}\rightarrow 160 / 65 \\
160 / 70 \rightarrow 130 / 70 \\
160 / 100 \rightarrow 130 / 75\end{array}$ & $\begin{array}{l}110 / 7 \\
110 / 70 \\
110 / 70\end{array}$ \\
\hline
\end{tabular}

P.D.A. = Patent ductus arteriosus. * Record lost. $\quad$ = Unobtainable by ordinary methods. 
ment, but femoral artery pulsation declined gradually and had disappeared by the end of 24 hours.

The fourth patient in this group (Case 4) had coarctation of an unusual kind. Narrowing of the aortic arch became progressively more severe during a period of two years (Fig. 4. A and B). A moderately long segment of aorta was affected and a Teflon graft was used for repair. Femoral artery pulses were full after operation, and an attack of abdominal pain and gastric bleeding was thought to be due to mesenteric arteritis. At about this time the boy complained of pins-and-needles in the left arm, and within a week it was impossible to feel a pulse at the groin. A month later venous angiography showed constriction of the aorta immediately distal to the lower end of the graft, an area where previously there had been no narrowing (Fig. $4 \mathrm{C}$ ). As the blood-pressure did not rise significantly it was decided to defer further surgical treatment until the graft had to be replaced.

\section{Group 2. Delayed Recurrence of Stenosis}

In this group of, cases surgical treatment gave satisfactory results for periods varying from a few months to several years. Development of secondary stenosis was a gradual process. For example, a boy (Case 5), whose femoral pulses were delayed but easily felt, deteriorated gradually during the four years after operation, so that a second operation was necessary at the age of 16. A long segment of aorta was narrowed by perivascular fibrosis and had to be replaced by a graft. As a result the volume of his femoral pulses increased, but in spite of this his brachial blood-pressure has not changed.

Two years after operation on another boy (Case 6) the femoral pulses were first observed to be feebler. Over the course of the next two years there was increasing clinical evidence of obstruction, and recurrence was confirmed by retrograde catheterization (gradient $30 \mathrm{~mm}$. $\mathrm{Hg}$ systolic) and aortography (Fig. 5). At the second operation a Teflon patch was inserted into the hypoplastic segment above the aortic stricture. He had several attacks of abdominal pain associated with breathlessness and faintness in the post-operative period. Femoral pulsation again disappeared, and the result of operation was at first

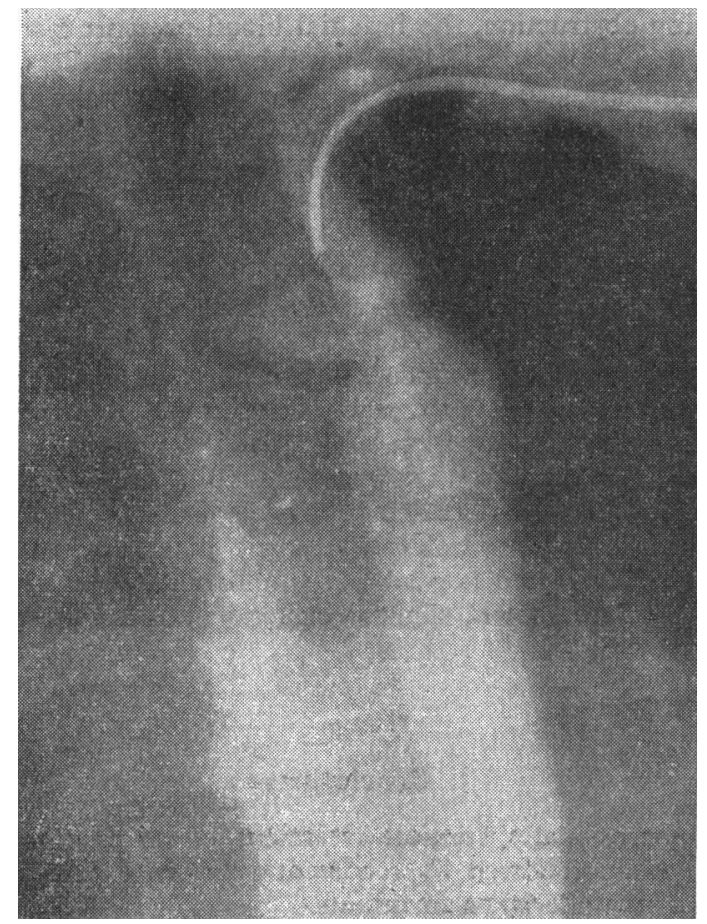

Fri. 5.-Case 6. Aortogram showing recurrence of coarctition after operation. regarded as disappointing; but over a three-months period the femoral pulses gradually increased in 'volume and the arm blood-pressure fell.

A baby (Case 7), whose coarctation was complicated by a hypoplastic aortic arch and a small ventricular septal defect (Fig. $6 \mathrm{~A}$ ), was treated surgically when 5 months old. Satisfactory femoral pulsation was obtained. Four months later the pulses were smaller, and five years later recurrence was demonstrated by catheter (gradient $60 \mathrm{~mm}$. $\mathrm{Hg}$ systolic) and aortogram (Fig. $6 \mathrm{~B}$ ). It was also demonstrated that the ventricular septal defect had closed spontaneously.

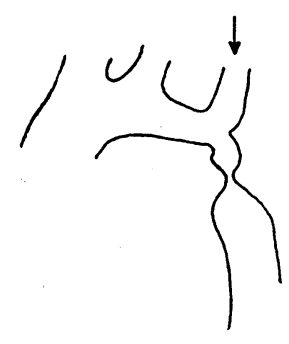

A

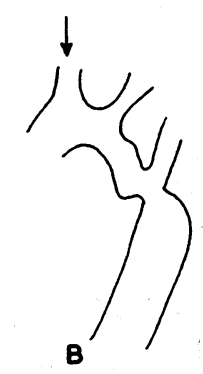

FrG. 6.-Case 7. A, Tracing of cineaortogram before operation, left oblique position, 19 March 1958. B, Tracing of cineaortogram 19 March 1958. B, Tracing of cineaortogram November 1963.

Repair of an infant's coarctation (Case 8), leaving the posterior aortic wall intact, excising an obstructing ridge within the lumen and increasing the circumference of the vessel by plastic repair, gave a satisfactory result for 18 months. Twn years after operation the femoral pulse could not be felt, but restenosis has not yet been confirmed.

Recurrent coarctation is not always relentlessly progressive, and the two remaining cases, which illustrate this, show how essential it is to confirm the recurrence by catheterization or aortography.

A boy (Case 9) was treated surgically when he was 13 years old. Femoral pulsation was not at first restored, and eight months later aortography confirmed that there was some degree of aortic narrowing (Fig. 7). However, he subsequently

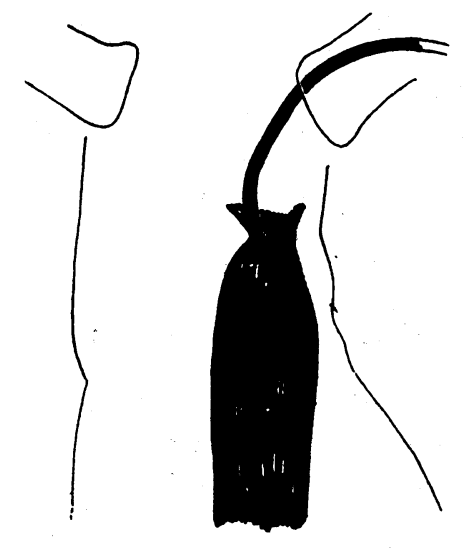

FIG. 7.-Case 9. Aortogram eight

improved, and eight years later his blood-pressure was satisfactory and femoral pulses were easily felt.

An infant (Case 10) with intractable heart failure had a ventricular septal defect in addition to coarctation. After excision of the narrow aortic segment the femoral pulses remained small and delayed, and the brachial blood-pressure was at first high. But six years later an aortogram (Fig. 8) showed minimal constriction, and catheterization confirmed that no pressure gradient existed across the anastomotic 
junction (B.P. 95/60 above, 94/60 below junction). Moreover, the ventricular defect was much smaller.

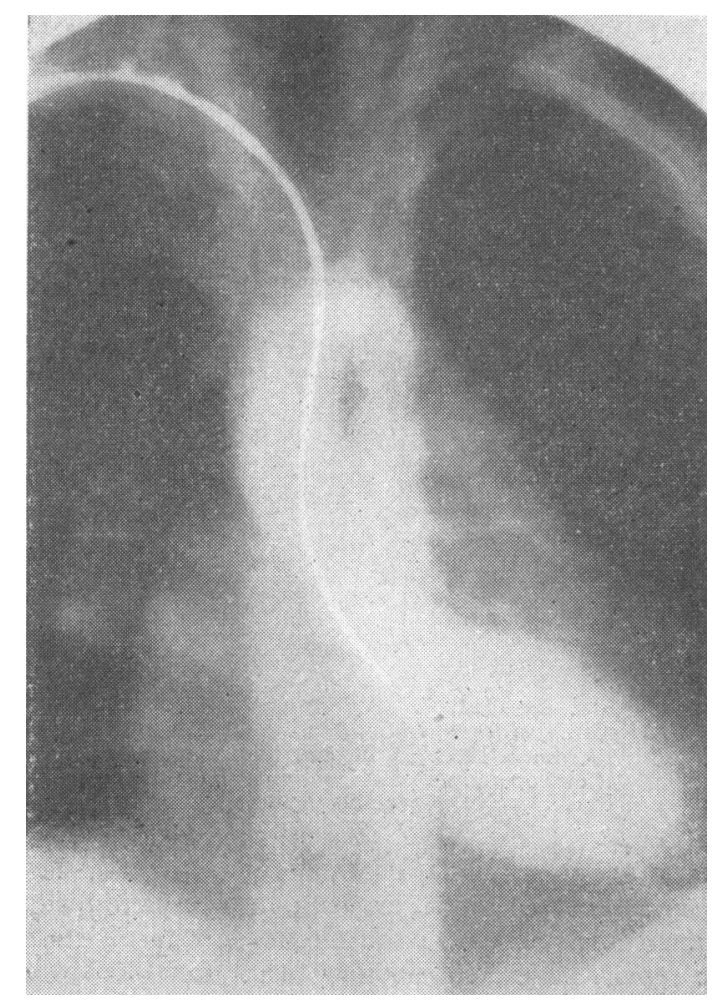

Fig. 8.-Case 10. Aortogram six years after operation.

\section{Discussion}

Case 1 is included in this paper solely as a reminder that unsuccessful surgery is immediately obvious ; the femoral pulse is not restored, even temporarily, and the brachial bloodpressure may rise above pre-operative levels. In no other patient did the surgeon doubt the success of the operation; serious technical difficulties did not occur, but a fall in bloodpressure and a readily felt femoral pulse immediately after operation was no guarantee that coarctation would not recur, sometimes quickly, sometimes slowly.

It may be impossible to construct an aortic arch of normal calibre from a hypoplastic segment. The use of grafts or a continuous suture to repair the aorta may interfere with aortic development and so prevent the anastomosis from growing as fast as the child. But none of these causes can explain our series of cases. Stenosis developed too quickly, and ultimately the lumen was much narrower than the anastomotic channel made by the surgeon. This was not just a passive failure of growth but an active shrinkage of the aortic lumen.

Rapid recurrence of obstruction might be due to clotting on the suture line. Two children had abdominal pain and vomiting after operation, and, not unnaturally, this was ascribed to mesenteric arteritis because the femoral pulse volume was large. However, at much the same time one child complained of a sensory disturbance affecting an arm; the other suddenly became faint and short of breath. Such symptoms might be explained by thrombo-embolism. Aortic obstruction followed shortly afterwards. If clotting does account for restenosis it is difficult to understand why it should be so uncommon, and it cannot wholly explain the slowly progressive recurrence of coarctation which we observed in four children. Evidence that naturally occurring coarctation may evolve gradually is illustrated by Fig. $4 \mathrm{~A}$ and $\mathrm{B}$. The first of these angiographic studies was obtained by chance when the child was being inviestigated for pulmonic stenosis. The brachial blood-pressure was $110 / 80$ and there was virtually no clinical evidence of coarctation. During the next two years signs slowly developed, and when the second aortogram was taken the femoral pulses could no longer be felt, the blood-pressure was $150 / 80$ in the arms and unobtainable in the leg.

Edwards et al. (1948) pointed out that the narrowing of coarctation might be progressive. They described a peculiar deformity of the aortic media, which projects into the lumen of the vessel, making it narrow and eccentric. This characteristic feature is seen even in infants-for example, Case 8 . In cross-section the thickened media has a sphincter-like appearance. In addition, adolescents and adults often have a localized area of fibrous intimal thickening, beneath which the medial structures are distorted. This is regarded as a "jet lesion," and, as it has a laminated structure and is rarely, if ever, seen in infancy, it is thought to be progressive and due to “. . . trauma by eddies of blood at the point of aortic narrowing."

This description seemed to fit the changes illustrated in Fig. $4 \mathrm{~A}$ and B. Dr. Donald Heath reported as follows on the aortic segment removed at operation: "Sections of the coarctation show a medial 'spur.' Intimal changes are not pronounced and the 'jet lesions' are not so prominent as one commonly finds. There is some intimal fibroelastosis with disruption of the internal elastic lamina. There is also considerable fibrosis of the underlying media, particularly affecting the inner half. There is no evidence of recent or organized thrombus in the lumen to account for the reported progressive diminution of the aortic lumen. The elastic tissue pattern of the outer half of the media is of normal aortic pattern. The media also contains excessive accumulations of metachromatic acid mucopolysaccharides."

The medial spur, by reducing the aortic lumen, might have initiated the mechanism of progressive narrowing. Rodbard $(1956,1958)$ has shown that when the velocity at which fluid flows through a tube is increased above a certain critical level there is a drop in the lateral or distending pressure, which results in narrowing of the lumen by cushion formation. He suggests that intimal cells are stimulated when the inhibiting effect of lateral pressure is reduced and that constriction is consequently progressive.

All patients in the present series had evidence of gradually increasing obstruction, the brachial blood-pressure rising, and the leg blood-pressure falling until it could not be obtained by auscultation (see Table). In two cases an initial impression of recurrence did not persist and eventually was proved to be mistaken. In these two cases aortography showed a minor degree of stricture but insufficient, presumably, to cause a critical change in blood velocity with its consequence of cushion formation at the point of narrowing.

On the basis of their own experience and a review of the literature Rathi and Keith (1964) conclude that operation at the age of 3 would produce a satisfactory aortic lumen even if the anastomosis failed to grow significantly. This conclusion depends on two suppositions: (1) that the aortic diameter at diaphragmatic level in the 3-year-old child is about $55 \%$ of that of an adult, and (2) that physiological obstruction does not become apparent unless the aortic diameter is less than $55 \%$ of the expected normal. It would not be valid if, as we believe we have shown, slight obstruction can initiate progressive narrowing.

\section{Conclusions}

Very occasionally surgical treatment of coarctation of the aorta may be followed by recurrent stenosis, especially when operation is undertaken in infants.

When surgery is ineffective the failure to relieve obstruction is immediately apparent. 
Sometimes surgery gives immediate relief but stenosis recurs after a period.

In the present series of cases neither continuous suture nor the use of grafts has been responsible for a failure of the anastomotic junction to grow with the child.

The evidence suggests that delayed recurrence has been due not to a passive process but to an actual shrinkage in the diameter of the aortic lumen. The rate of progression varied considerably.

The underlying cause of recurrent stricture has not been determined. In some cases it may be due to perivascular inflammation; in others incomplete relief of obstruction or clotting on the suture line may lead to disturbance of bloodflow, and this in turn may promote narrowing by initiating some other mechanism.

Heart failure which does not respond to medical treatment is an indication for operating on coarctation in infancy. This is especially the case when coarctation is complicated by a ventricular septal. defect. In two cases the septal defect diminished in size after operation on the aorta.

\section{Summary}

In a number of infants and children coarctation of the aorta has recurred after what appeared to be satisfactory surgical treatment. Contrast radiography, catheterization, and further operation have been used to confirm restenosis. The condition was not due to failure of the anastomotic junction to grow after operation. The narrowing developed in a progressive manner, and in some cases resulted in almost complete obliteration of the aortic lumen. Possible reasons are advanced to explain this phenomenon, but none is completely satisfying.

We are grateful to our surgical colleagues for their generosity in allowing us to report this series of cases, and to Dr. Donald Heath for the pathology report.

\section{REFERENCES}

Blackford, L. M. (1928). Arch. intern. Med., 41, 702.

Bull, C., Hoeksema, T., Duckworth, J. A., and Mustard, W. T. (1963). Canad. 9. Surg., 6, 383.

d'Abreu, A. L., and Parsons, C. (1956). Brit. med. F., 2, 390.

Edwards, J. E., Christensen, N. A., Clagett, O. T. and McDonald, J. R. (1948). Proc. Mayo Clin., 23, 324.

Freundlich, E., Engle, M. A., and Goldberg, H. P. (1961). Pediatrics, $27,427$.

Lang, H. T., and Nadas, A. S. (1956). Ibid., 17, 45.

Mustard, W. T., Rowe, R. D., Keith, J.' D., and Sirek, A. (1955). Ann. Surg., 141, 429.

Nadas, A. S. (1963). Pediatric Cardiology, 2nd ed. Saunders, Philadelphia.

Rathi, L., and Keith, J. D. (1964). Brit. Heart f., 26, 671.

Reffenstein, G. H., Levine, S. A., and Gross, R. E. (1947). Amer. Heart 3., 33, 146.

Rodbard, S. (1956). Ibid., 51, 926.

(1958). Circulation, 17, 410.

Schuster, S. R., and Gross, R. E. (1962). 7. thorac. cardiovas. Surg. 43, 54.

Sellors, T. H., and Hobsley, M. (1963). Lancet, 1, 1387.

\title{
Serum Lactic Dehydrogenase Activity and Folate Deficiency in Myelosclerosis and other Haematological Diseases
}

\author{
A. V. HOFFBRAND, $* \dagger$ M.A., B.M., M.R.C.P., D.C.P.; S. KREMENCHUZKY, $* \dagger \S$ M.B. \\ P. J. BUTTERWORTH, M.SC.; D. L. MOLLIN, $\neq$ M.B., B.SC., M.R.C.P.
}

Brit. med. F., 1966, 1, 577-581

The serum lactic dehydrogenase activity is raised in a number of haematological diseases, especially pernicious anaemia (Hess and Gehm, 1955 ; Heller, Weinstein, West, and Zimmerman, 1960), megaloblastic anaemia due to folate deficiency (Gordin and Enari, 1959; Fleming and Elliott, 1964), haemolytic anaemia (Zimmerman and Weinstein, 1956), myelosclerosis (Levitan, Wasserman, and Wróblewski, 1960), and leukaemia (Hsieh and Blumenthal, 1956 ; Vesell and Bearn, 1961).

The exact cause for the raised serum lactic dehydrogenase levels in these diseases is unknown, but it is possible that they are produced by increased cell turnover with breakdown of primitive cells in the bone-marrow. Such a mechanism has been suggested to cause raised serum lactic dehydrogenase activity in pernicious anaemia (Heller et al., 1960). Chanarin, Mollin, and Anderson (1958) postulated that increased marrowcell turnover can produce folate deficiency. It could be, therefore, that serum lactic dehydrogenase activity parallels the incidence and severity of folate deficiency in haematological

\footnotetext{
* M.R.C. Group for Research into Megaloblastic and Sideroblastic Anaemias and the Department of Haematology, Postgraduate Medical School of Landon.

t Department of Chemical Pathology, Postgraduate Medical School of London.

$¥$ In receipt of a grant from the Medical Research Council.

With a fellowship from the "Consejo Nacional de Investigaciones Científicas y Técnicas," Argentina.
}

diseases in which bone-marrow activity is increased. The main purpose of the present study was to test this hypothesis by directly comparing serum lactic dehydrogenase and serum folate levels in a number of such diseases.

In addition serum lactic dehydrogenase was measured in anaemic and non-anaemic patients with folate or vitamin- $B_{12}$ deficiency due to gastro-intestinal disorders to see the effect of these deficiencies per se on serum lactic dehydrogenase activity. During the course of the study it became apparent that the measurement of serum lactic dehydrogenase could be useful the diagnosis of myelosclerosis, and this point is also discussed.

\section{Methods}

1. Serum lactic dehydrogenase was determined by the method of Wróblewski and LaDue (1955). All sera were separated one or two hours after the blood was collected, and, if not assayed immediately, were stored at $4^{\circ} \mathrm{C}$. until the time of estimation. The storage period was usually less than 24 hours and never more than three days. The enzyme estimation was carried out at $25^{\circ}$ C. in a Unicam SP 500 spectrophotometer fitted with a constant-temperature device, and the reaction rate was found to be linear throughout the five-minute period of observation. 